\title{
Mesoscale Power Generation by a Catalytic Combustor using Electrosprayed Liquid Hydrocarbons
}

\author{
Dimitrios C. Kyritsis ${ }^{+}$, Ismael Guerrero-Arias ${ }^{+}$, Subir Roychoudhury ${ }^{\S}$ and Alessandro Gomez ${ }^{+*}$ \\ ${ }^{+}$Yale Center for Combustion Studies \\ Department of Mechanical Engineering, Yale University \\ New Haven, CT 06520-8286 \\ ${ }^{\S}$ Precision Combustion Inc., North Haven, CT 06473 \\ * author for correspondence: fax: (203) 432 7654, email: alessandro.gomez@yale.edu
}

\begin{abstract}
The development of a mesoscale catalytic combustor to be coupled with direct energy conversion modules for power production is presented. The combustor has a volume on the order of few $\mathbf{~ c m}^{3}$ and operates on JP8 jet fuel, which is electrosprayed at a flow rate on the order of $10 \mathrm{~g} / \mathrm{hr}$ and equivalence ratios varying from 0.35-0.70. Temperatures in the range $900 \mathrm{~K}-1300 \mathrm{~K}$ are achieved with a $\pm 5 \%$ uniformity over the top circular surface of the burner. Using gas chromatographic analysis of the exhaust gases, a combustion efficiency on the order of $97 \%$ is estimated. Remarkably, no fouling, nor soot, nor NOx were detected in the exhaust gases, which resulted in clean and efficient combustion of even environmentally problematic liquid hydrocarbons.
\end{abstract}

Colloquium: New Concepts in Combustion Technology

Keywords: Micro-combustors, Electrospray

Word Count:

Text:

5 figures: 5 x 200

1,000

1 double figure: 1 x 400

400

1 equation: 1 x 21

21

References: 23 lines x 7

161

Total:

5,266 


\section{Introduction}

The development of MEMS (Micro-Electro-Mechanical-Systems) technology in the last ten years has spurred interest in the realization of combustion at scales much smaller than previously explored. The primary incentive to use combustion stems from the large power density of liquid hydrocarbon fuels, on the order of $42 \mathrm{MJ} / \mathrm{Kg}$, that is, two orders of magnitude larger than that of the best (e.g. Lithium ion) batteries available on the market today. A successful program in this area would lead to the development of the ultimate distributed power source that may replace batteries in all kinds of applications, ranging from portable electronics to powering Micro Air Vehicles (MAV) and other military applications.

Combustion at small scales presents numerous challenges. As size decreases, the combustor surface-to-volume ratio increases. This, in turn, is a rough indicator of the ratio between heat loss and heat release rates. At a sufficiently small scale, losses will be too high for combustion to be sustained and extinction will occur. Control of quenching problems requires a careful design and a judicious selection of operating conditions and wall materials, and ultimately sets a lower limit to the combustor dimensions. The short residence times in a small scale combustor may prevent complete fuel conversion to $\mathrm{CO}_{2}$ and $\mathrm{H}_{2} \mathrm{O}$, reduce heat release and create emission of pollutants such as $\mathrm{CO}$ and unburned hydrocarbons, which suggests the use of catalytic techniques for pollutant abatement and maximization of the combustor efficiency.

Most of the recent and often non-archival literature in this nascent field is reviewed in [1]. Efforts in this area can be classified into two main categories. A first category involves micro- or mesoscale devices operating on conventional power cycles, e.g. gas turbines [2] and IC engines [36]. In this approach, problems arise concerning balancing rotary components at high speed and sealing as well as micro-fabrication difficulties stemming from the intricacy of the geometrical configuration and the necessary tight tolerances. The second category involves a first stage of 
combustion under steady state conditions, which could then be coupled to a direct energy conversion module such as a thermoelectric (TEG) [7,8] or thermophotovoltaic (TPV) generator. The advantage of fabrication simplicity of the second approach is often offset by the low efficiency of direct energy conversion (currently not higher than 15\% [9-11]). However, if the approach is applicable to liquid hydrocarbons, the advantage of liquid fuels in power density should provide some latitude with respect to the acceptable efficiency of the subsequent energy conversion scheme, which makes this alternative still feasible. For all these approaches, difficulties in heat management at the small scales arise, which may reduce significantly both the efficiency and the power density of such devices. Such difficulties are particularly severe in microscale applications (order of a few $\mathrm{mm}$ ) but more manageable at the mesoscale (order of a few $\mathrm{cm}$ ).

The present contribution falls in this second category. The emphasis is on the combustion design to burn liquid fuels at steady state in a chamber with characteristic dimensions on the order of a few cm, thereby bypassing quenching issues, arising at sub-millimeter scales [12] and extracting some of the thermal energy conversion processes with a minimum of moving parts. Even at such a mesoscale, the adaptation of fabrication techniques that have been developed for the solidstate electronics industry may be necessary because design features (contouring, streamlining, coating, multiplexing, etc.) need to be resolved at the sub-millimeter scale.

\section{Burner design}

\section{Liquid dispersion}

Preliminary estimates of the target overall system efficiency $(\approx 20 \%)$ for the delivery of 20 $\mathrm{W}$ of electric power using state-of-the-art thermal-to-electric energy conversion schemes resulted in a combustion power output on the order of $100 \mathrm{~W}$, which translates in a liquid mass flow rate of 7-

$8 \mathrm{~g} / \mathrm{hr}$ for the typical heating value of a liquid hydrocarbon. For military applications the fuel of choice is a jet fuel, such as JP8, because of its availability in the battle field. Combustion can be 
implemented after the liquid fuel has been either pre-vaporized in micro-channels or sprayed. A potential difficulty in vaporizing thin films of heavy hydrocarbons, as suggested for alcohols in [13], is that the fuel decomposes thermally in the presence of hot surfaces, in which case fouling and plugging of the miniaturized channels may ensue. The problem is particularly severe at the location where the phase change occurs and is affected by the residence time [14].

In view of such difficulties liquid atomization was deemed the alternative of choice, for which virtually the only candidate suitable at the small flow rate of interest is electrospray atomization $[\mathbf{1 5 , 1 6 ]}$. The electrospray is defined here as a system in which the dispersion of the liquid relies solely on its electric charging. Such a system can be implemented by feeding a liquid with sufficient electric conductivity and moderate surface tension through a small orifice maintained at a high potential relative to a ground electrode a short distance away. This approach offers enhanced vaporization and mixing because of the presence of net charge on the surface of the generated droplets.

\section{The need for catalytic combustion}

TEG, TPV techniques and Alkali Metal Thermal to Electric Conversion (AMTEC) are some of the potential candidates for subsequent combustion interfacing. The specific technique affects combustion only with respect to the temperature that is desirable at the interface with the energy conversion module, which is anticipated to be in the range of 900-1500 K, and its uniformity. In view of the relatively low combustion temperatures, catalytic combustion offers the necessary prerequisite of stability. The feasibility of catalytic oxidation was demonstrated in micromachined reactors in low temperature silicon-based systems [17].

Particularly well-suited for small scale applications is a recently developed catalyst substrate design (Microlith ${ }^{\circledR}$ ) [18]. It consists of a number of catalytically coated grids or screens, each with short channel lengths, high cell density and low thermal mass, stacked serially. The 
resulting reactor is very compact, has rapid transient response and high energy density, and requires small loadings of precious metal catalysts. Catalyst formulations have been selected from platinum group metals and an alumina washcoat with appropriate additives. The advantages of this design stem from the reduction in mass transfer limitations, as compared to conventional monoliths having relatively thick boundary layers. Also, under conditions of kinetic control the particular design can pack more active area into a small volume, which means that insertion of such catalysts in a flow can provide more effective fuel conversion for a given pressure drop.

\section{A case for multiplexing liquid dispersion}

The main drawbacks in burning the entire flow rate from a single source is that it is difficult to achieve the required degree of uniformity of surface temperature for subsequent energy conversion and to maintain small combustor dimensions. Thus, we partitioned the total liquid flow rate into a multitude of small electrosprays. The main advantages of multiplexing are twofold. First, by diminishing the flow rate through each capillary, the generated droplet size is also reduced, since the latter scales with flow rate approximately as $d \propto Q^{2 /}$ [19]. For example, if the total flow rate dictated by energy requirements is partitioned into $\mathrm{n}$ electrosprays, the droplet size at the injection is reduced by $(1 / \mathrm{n})^{2 / 3}$ and since, in the first approximation, the droplet evaporation time varies with the square of the droplet diameter, the evaporation time should be reduced by $(1 / \mathrm{n})^{4 / 3}$. Second, establishing a shroud flow of oxidizer around each spray ensures that the mixing occurs rapidly and homogeneously. A potential disadvantage of multiplexing is that the spray spreading in the radial direction may be affected by space charge effects, namely the interaction of homopolarly charged sprays that would repel one another.

Igniting in the vicinity of the electrospray source and burning in a diffusion-controlled mode $[15,16]$ would require subsequent mixing with secondary air to achieve the desired, relatively low temperatures for subsequent energy conversion. This approach is likely to result in larger 
combustor volumes. Conversely, one could ignite farther downstream after substantial mixing with the oxidizer has occurred, using a gauze or honeycomb to separate the combustion region from the electrospray and to prevent flashback. This premixed combustion alternative was explored decades ago in some pioneering work by Thong and Weinberg [20]. Here, we consider the catalytic alternative, in which the Microlith ${ }^{\circledR}$ acts both as catalyst and stabilizing grid for the flames.

\section{Experimental apparatus}

A photograph of the experimental burner is shown in fig. 1 The fuel was metered with a syringe pump. The burner was operated with three fuels, all of them with $0.3 \%$ per mass of an antistatic additive (Stadis 450, Du Pont). The fuels were JP8 jet fuel, n-dodecane which is the single component-fuel the physical properties of which are closest to JP8 [18] and 1,3 di-isopropylbenzene which has structure and properties similar to the most common aromatics in JP8 [21,22]. For the results to be reported here, the flow was distributed through a PEEK manifold into seven stainless steel capillaries (1.59 mm O.D., $127 \mu \mathrm{m}$ I.D.,10 cm length) arranged in a hexagonal pattern. The capillaries were mounted through a teflon flange and their tips were sharpened and polished to eliminate burs that would affect the electric field pattern. In the future, more extensive multiplexing, on the order of 100 electrosprays in parallel, is planned by microfabrication techniques that have already been applied to the electrospray for chemical analytical applications [23]. The flange supported a cylindrical pyrex chamber $38.1 \mathrm{~mm}$ in I.D. and $38.1 \mathrm{~mm}$ in height that provided optical access. Air was provided through the flange into the chamber at a temperature of $200^{\circ} \mathrm{C}$ to simulate recuperation in a real device. The chamber was capped at the top with a metal holder in which the Microlith ${ }^{\circledR}$ catalyst screens were housed. Each screen was an approximately orthogonal grid of $125 \mu \mathrm{m}$ wires with $1 \mathrm{~mm}$ pitch. Once the capillaries were charged to a voltage on the order of several $\mathrm{kV}$ relative to the catalyst holder that was grounded, seven electrosprays were simultaneously established at the capillary tips. The pressure loss across the capillaries is

minimal, i.e. approximately $20 \mathrm{~cm}$ of water ( 2 kPa), and was measured by supplying the liquid 
gravimetrically. The pressure drop across the catalyst grid is so small that it can not be measured accurately $(<1 \mathrm{kPa})$. The power consumption of the electrosprays is minimal. The current carried by the sprays was measured to be on the order of $100 \mathrm{nA}$, which yields a parasitic loss of less than $1 \mathrm{~mW}$ for approximately $100 \mathrm{~W}$ of thermal power.

The temperature on the catalyst surface was measured using a PV-320 Electrophysics infrared video camera and a germanium objective lens. To avoid signal saturation, a glass filter of 0.3 optical density and a $2.5 \mu \mathrm{m}$ cut-off was used, so that the recorded signal on the camera chip was from the 1.5-2.5 $\mu \mathrm{m}$ part of the spectrum. The temperature measurements were calibrated using a K-type thermocouple coated with the catalyst material. Exhaust gas sampling downstream of the catalyst was used to determine exhaust gas composition. Major combustion products and light species $\left(\mathrm{N}_{2}, \mathrm{O}_{2}, \mathrm{H}_{2}, \mathrm{CO}_{2}, \mathrm{CO}, \mathrm{CH}_{4}, \mathrm{C}_{2} \mathrm{H}_{6}\right.$, and in general hydrocarbons with three or less atoms of carbon) were measured using a two-channel Micro-Gas Chromatograph of Agilent Technologies. The device employs two channels, one with a molsieve and one with a PoraPLOT backflush injector. Acquisition of an exhaust gas sample lasted $60 \mathrm{~s}$ and argon was used as a carrier gas for both injectors.

\section{Results and discussion}

The objective of the fuel delivery system is to produce a lean, uniform mixture of fuel and air upstream of the catalyst. The mixture should burn completely as it passes through the screens and provide a uniform surface temperature in the range $900 \mathrm{~K}-1500 \mathrm{~K}$, for subsequent coupling with direct energy conversion modules. The mechanism of electrospray atomization, which determines the quality of air-fuel mixing, was studied in detail for isolated electrosprays in [19]. Because of space charge effects, the results of such studies are only of qualitative validity when multiplexed sprays are considered. The appearance of these sprays for JP8 injection is shown in the photograph of fig.2, which was taken without the pyrex chimney and in the absence of combustion. Similar 
photographs during actual operation are less informative due to reflections on the pyrex tube but show a similar structure. A cone of liquid fuel was formed on each capillary tip from which a short fluid ligament protruded. Atomization was achieved through the breakup of these ligaments similar to [19], and the Coulombic repulsion among droplets of different sprays facilitated fuel dispersion. The length of the plumes in fig. 2 was on the order of $5 \mathrm{~mm}$ and is expected to be significantly smaller during actual operation because of heat diffusion from the reaction region.

The degree to which uniformity of equivalence ratio is achieved by the time the mixture reaches the catalyst determines the quality of the performance of the device. To characterize such a performance, the surface temperature of the screens and the exhaust gas composition were measured and their uniformity was investigated. From the exhaust gas composition, the combustion efficiency can be determined.

A two dimensional map of temperature on the catalyst screen acquired with infrared photography is presented in fig. 3 for JP8 fuel, at an equivalence ratio $\phi=0.48$ and a fuel flow rate of $9.8 \mathrm{~g} / \mathrm{hr}$. The dark holes in the pattern are void regions through which the exhaust gases flow. Radial temperature scans on the catalytic screen with data acquired from the thermography pictures are presented in fig.4a for $\phi=0.48$ and a fuel flow rate of $12.6 \mathrm{ml} / \mathrm{hr}$ for three different fuels: JP8, n-dodecane 1,3 di-isopropyl-benzene. There is a $\pm 5 \%$ variation around the mean value and a mild temperature gradient across the screen for the two single-component fuels. Better uniformity of the equivalence ratio is achieved with JP8, possibly because of the presence of lighter components which vaporize faster and mix more effectively than the heavier fuels. A maximum temperature of approximately $1100 \mathrm{~K}$ is achieved which is within the range of target temperatures for direct energy conversion. This temperature is significantly lower than the adiabatic flame temperature of e.g. dodecane for the same equivalence ratio, that is $1550 \mathrm{~K}$. An energy balance in a control volume surrounding the screens yields:

$$
\frac{d m_{f}}{d t} Q_{L H V}=\frac{d m}{d t} c_{p}\left(T-T_{o}\right)+\varepsilon \sigma A\left(T^{4}-T_{o}^{4}\right)+Q_{c o n d}^{\prime}
$$


where $m$ and $m_{f}$ are total and fuel mass respectively, $Q_{L H V}$ the lower heating value of the fuel, $\varepsilon$ the emissivity of the catalyst material which was approximated as the one of the steel material of the wires, $A$ the radiating surface which can be estimated from the dimensions of the Microlith ${ }^{\circledast}$ and $Q_{\text {cond }}$ the heat loss due to conduction through the catalyst material and the rest of the burner hardware. $Q_{\text {cond }}$ is difficult to measure directly but substitution into eq.1 yields that it must be on the order of $15 \%$ of the total energy input, which is entirely conceivable for the current experimental set up. Selection of appropriate insulating materials or heat management schemes should reduce this loss and make the same temperatures of operation possible for even leaner mixtures.

The maximum temperature as a function of equivalence ratio for a given fuel mass flow rate is shown in fig. $4 \mathrm{~b}$ for JP8 combustion. The equivalence ratio was varied by changing the air flow. Since the overall stoichiometry is always lean, the temperature should increase with equivalence ratio. Yet, an increase of the equivalence ratio from 0.40 to 0.53 results in an increase in the temperature on the catalyst by only $100 \mathrm{~K}$, whereas the calculated adiabatic flame temperature increases by approximately $500 \mathrm{~K}$. The temperature on the catalyst appears to decrease for $\phi>0.53$.

\section{This is likely due to the change in residence times within the catalyst.}

The fact that the operation of this experimental burner is heat loss limited is shown more clearly by the dependence of maximum temperature on fuel flow for fixed $\phi=0.48$, as shown in fig. 4c. If the equivalence ratio is kept constant, the adiabatic flame temperature is expected to be constant. This is not the case for non-adiabatic operation. The energy input to the system (left hand side of eq.1) is proportional to the fuel flow rate, which in turn is proportional to total flow rate, since $\phi$ is fixed. The heat loss (two last terms on the right hand side) is mainly determined by the geometric and heat transfer properties of the system, which do not correlate with the flow rate equally strongly. As a result, a decrease in flow rate results in a lower temperature on the catalyst. There is actually a threshold fuel flow rate $(\approx 6 \mathrm{~g} / \mathrm{hr})$ below which operation can not be sustained. On the other hand, if the flow rate is increased above a limit, $(\approx 25 \mathrm{~g} / \mathrm{hr})$ the residence time in the 
burner is not sufficient for the fuel to react and the mode of operation changes completely with the establishment of a partially premixed flame in the gaseous phase downstream of the catalyst screens.

Even though operation of the burner with a commercially available fuel blend has been established, it is preferable to investigate the composition of the exhaust gases for a single component fuel, for which the stoichiometry can be calculated precisely and the combustion efficiency can be calculated more accurately. For a base case of operation with n-dodecane with $\phi=0.48$ and a fuel flow rate of $9.7 \mathrm{~g} / \mathrm{hr}$, gas chromatographic measurements of mole fractions of the main components, $\mathrm{N}_{2}, \mathrm{O}_{2}, \mathrm{CO}_{2}$ and $\mathrm{CO}$, in a dry sample from the exhaust gas yielded $81.5 \%$, $11.5 \%, 6.4 \%, 0.11 \%$, respectively. Light hydrocarbons like $\mathrm{CH}_{4}$ and $\mathrm{C}_{2} \mathrm{H}_{6}$ as well as $\mathrm{H}_{2}$ were below the detection threshold of the particular GC apparatus (50 ppm). The corresponding composition of the exhaust gas mixture for complete combustion can be easily calculated as $81.9 \% \mathrm{~N}_{2}, 11.3 \% \mathrm{O}_{2}$ and $6.8 \% \mathrm{CO}_{2}$. The proximity of the exhaust gas composition to the one for complete combustion and the fact that no light hydrocarbons were detected indicates that combustion is very efficient. We can estimate this efficiency by assuming that all of the $0.4 \%$ deficit in the measured molar balance consists of combustible material and has to be counted as a loss. To this loss we add the percentage of carbon which turns to $\mathrm{CO}$ which is estimated by the $\mathrm{CO} / \mathrm{CO}_{2}$ ratio. This way, an efficiency of $97 \%$ is estimated.

The ratio of $\mathrm{CO}_{2} / \mathrm{CO}$ can thus be used as a measure of combustion efficiency and is presented in fig. 5 as a function of equivalence ratio for a mass flow rate of fuel equal to $9.7 \mathrm{~g} / \mathrm{hr}$. In the same figure, the mole fraction of $\mathrm{CO}$ in a dry sample from the exhaust gases is presented. Maximum $\mathrm{CO}$ to $\mathrm{CO}_{2}$ conversion is achieved for $\phi \approx 0.47$, close to $\phi \approx 0.53$ for which maximum temperature is achieved on the catalyst screen. The discrepancy is probably due to the fact that the $\mathrm{CO}_{2} / \mathrm{CO}$ ratio correlates but is not exactly equal to the combustion efficiency. More detailed 
analysis of the exhaust gas composition is expected to yield a value of $\phi$ for maximum efficiency even closer to the corresponding one for maximum temperature.

Figure 6 shows the $\mathrm{CO}_{2} / \mathrm{CO}$ molar ratio and the mole fraction of $\mathrm{CO}$ in a dry sample from the exhaust gases as a function of the fuel mass flow rate for an equivalence ratio $\phi=0.48$. Since the equivalence ratio is fixed, fuel flow rate is proportional to total flow rate and inversely proportional to residence time in the burner. As residence time decreases, it is clear that the $\mathrm{CO}$ to $\mathrm{CO}_{2}$ conversion is kinetically more limited and less effective. The corresponding slight increase in temperature shown in fig.4c is apparently not sufficient to counterbalance the effect of reduced residence time. The relatively large ratios of $\mathrm{CO}_{2} / \mathrm{CO}$ in figs. 5 and 6 suggest that the majority of the fuel conversion occurs on the catalyst. More extensive analysis of the exhaust gas composition may reveal the presence and quantities of pollutants other than $\mathrm{CO}$ in the exhaust gases, such as unburned hydrocarbons. An accurate calculation of the combustion efficiency involves more detailed measurements of the unburned hydrocarbons in the exhaust so that a carbon balance can be determined. Preliminary results from microprobe gas sampling and online photoionization massspectrometry seem to confirm the above estimate of combustion efficiency. A study focused on fuel conversion chemistry and on the pollutant emission is currently in progress.

\section{Summary and Conclusions}

A clean and efficient mesoscale combustor for power generation from liquid hydrocarbons, has been developed. Difficulties associated with the combustion of even kerosenetype fuels, such as JP8, were circumvented with a novel combination of fuel electrostatic spraying and catalytic combustion. Dispersion of the liquid fuel and subsequent mixing and vaporization were achieved in a small volume by electrospraying, which required minimal power and no elevated pressures. No significant amount of surface fouling, that is typically observed when the phase change of JP8 takes place near solid surfaces, was observed. Neither soot nor 
gaseous pollutants, except for a small amount of unburned hydrocarbons, were detected and almost complete conversion of $\mathrm{CO}$ to $\mathrm{CO}_{2}$ was achieved, despite the low combustion temperatures and the relatively short residence times. The output of the burner is a uniformly hot surface at a temperature appropriate for coupling with direct energy conversion modules.

Specifically, testing was performed at a fuel flow rate on the order of $10 \mathrm{~g} / \mathrm{hr}$ and an equivalence ratio ranging from 0.35 to 0.70 . Depending on equivalence ratio and mass flow rate, the temperature on the catalyst surface varied in the range $950-1200 \mathrm{~K}$, with a $\pm 5 \%$ uniformity over the surface. Combustion efficiencies on the order of $97 \%$ were achieved for operation with n-dodecane, a hydrocarbon with physical properties similar to those of JP8.

\section{Acknowledgements}

We would like to acknowledge Mr. R.W. Dean of PCI for his assistance with the micro-GC measurements and Mr. N. Bernardo of Yale University for machining the hardware. The support of DARPA, under Grant No. DAAD19-01-1-0664 (Dr. Richard J. Paur, Contract Monitor) is gratefully acknowledged. Microlith ${ }^{\circledR}$ is a trademark of Precision Combustion. Inc. 


\section{References}

1. Walther D.C.and Fernandez-Pello A.C., Inited Paper V, ESSCI Meeting, Dec. 2001.

2. Waitz, I.A., Gauba, G., and Tzeng, Y., J. Fluids Eng. 120 : 109 (1998).

3. Fu K., Knobloch A., Martinez F., Walther D.C.,Fernandez-Pello A.C., Pisano A.P., Liepmann D., Miyaska K. and Maruta K., Proc. IMECE (2001)

4. http://www.me.berkeley.edu/mrcl/why.html

5. http://www.arpa.mil/mto/mems/summaries/projects/Honeywell_25.html

6. Mijit K. Design, analysis and experimentation of a micro internal combustion swing engine. Ph.D. Thesis, University of Michigan, Ann Arbor MI, 2000

7. Sitzki L., Borer K., Wussow S., Schuster E., Maruta K., Ronney P.D.,Cohen A., AIAA Paper No. 2001-1087 (2001)

8. Milius D.L., Vartulli J.S., Aksay I.A., Gajdeczko B.F., Vican J., Dryer F.L., and Yetter R.A., Paper No. 87, ESSCI, Dec. 2001.

9. Anatychuk L.I., Proceedings of the $17^{\text {th }}$ International Conference on Thermoelectrics: 9 (1998)

10. Mahan G.D., Solid State Phys. 51: 81 (1998)

11. Mahan G.D., Sales B., Sharp J., Physics Today 3/97: 42 (1997)

12. Masel R. and Shannon M., Patent \# US06193501

13. Sirignano W.A., Paper No. 87, ESSCI, Dec. 2001.

14. Edwards T., AIAA Paper No. 92-0687 (1992).

15. Chen G. and Gomez A., Comb. Flame 110: 392 (1997).

16. Chen G. and Gomez A., Combust. Sci. and Tech 115: 177 (1996).

17. Srinivasan R., Hsing I-M., Berger P.E., Jensen K.F., Firebaugh S.L., Schmidt M.A., Harold M.P., Lerou J.J., Ryley J.F., AIChE. J 43: 3059 (1997).

18. Pfefferle W.C. US Patent No. 5,051,241, Precision Combustion, Inc. (1991). 
19. Tang K. and Gomez A., J. Colloid \& Interface Sci. 184: 500 (1996)

20. Thong, K. C. and Weinberg, F. J., Proc. Roy. Soc. Lond. A, 324: 201 (1971).

21. Edwards T.and Maurice L.Q., J. Prop. \&Power 17:461 (2001)

22. Violi A., Yan S., Eddings E.G., Sarofim A.F., Granata S.,Faravelli T., Ranzi E., $2^{\text {nd }}$ International Mediterranean Combustion Symposium Jan.6-11, 2002,Sharm El-Sheikh, Egypt.

23. Tang K., Lin Y., Matson D.W., Kim T., and Smith R.D., Anal. Chem 73: 1658 (2001) 


\section{Figure captions}

1. Experimental catalytic mesoscale burner operating on JP8 fuel.

2. Atomization pattern for electrospraying of JP8 into ambient air conditions.

3. Two-dimensional map of temperature on the catalytic screen acquired with infrared photography.

4. a) Radial distribution of temperature across the catalyst; b) Maximum surface temperature as a function of the equivalence ratio; c) Maximum surface temperature as a function of the fuel mass flow rate. (O: JP8, $\triangle$ :n-dodecane, $\square:$ 1,3 di-isopropyl-benzene)

5. $\mathrm{CO}$ mole fraction $(\square)$ and $\mathrm{CO}_{2} / \mathrm{CO}$ ratio on a molar basis $(\mathbf{O})$ as a function of equivalence ratio for a fixed fuel flow rate of $9.7 \mathrm{~g} / \mathrm{hr}$.

6. $\mathrm{CO}$ mole fraction $\left(\square\right.$ and $\mathrm{CO}_{2} / \mathrm{CO}$ ratio on a molar basis $(\mathbf{O})$ as a function of fuel mass flow rate for a fixed $\phi=0.48$. 


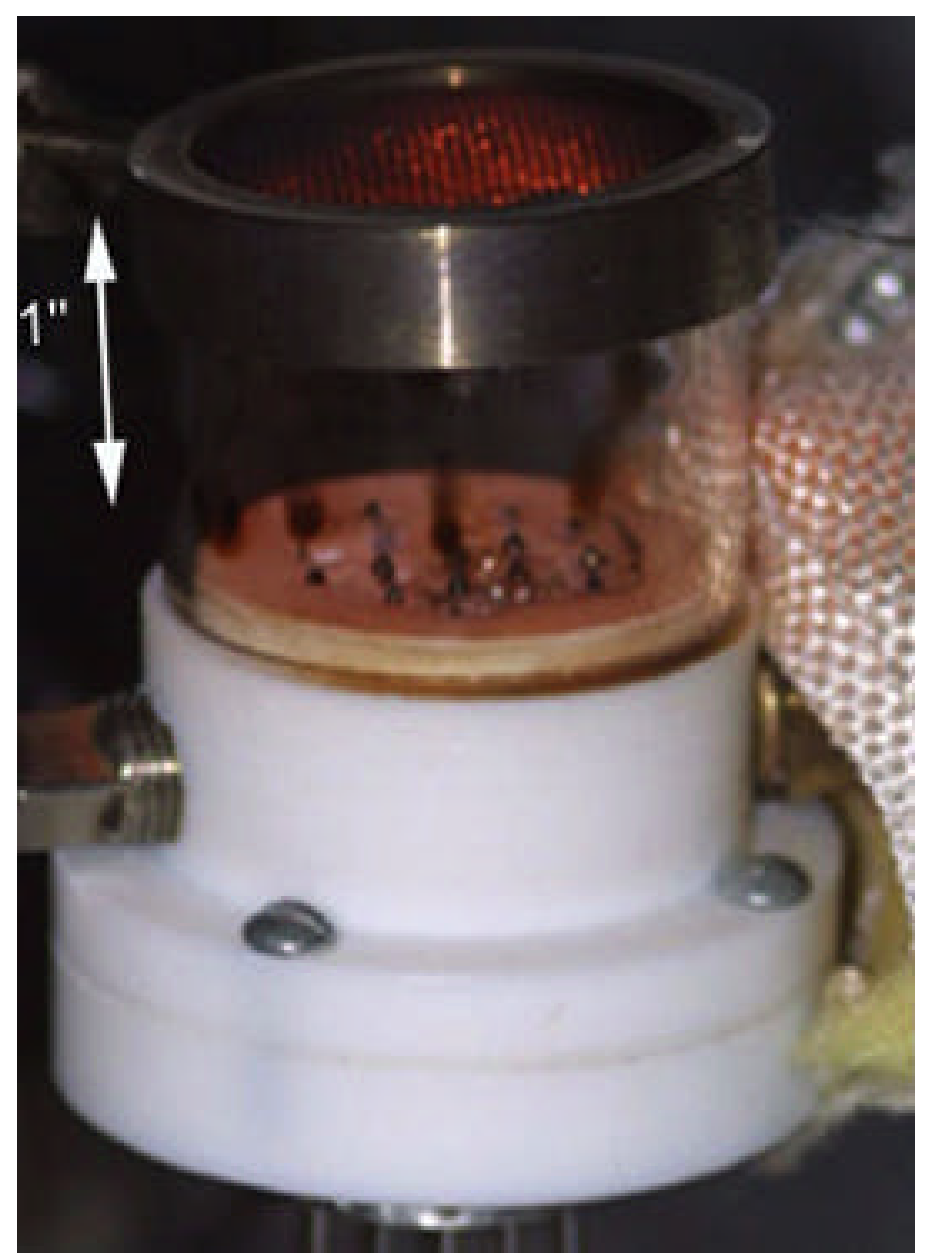

Fig.1. Kyritsis et al. 


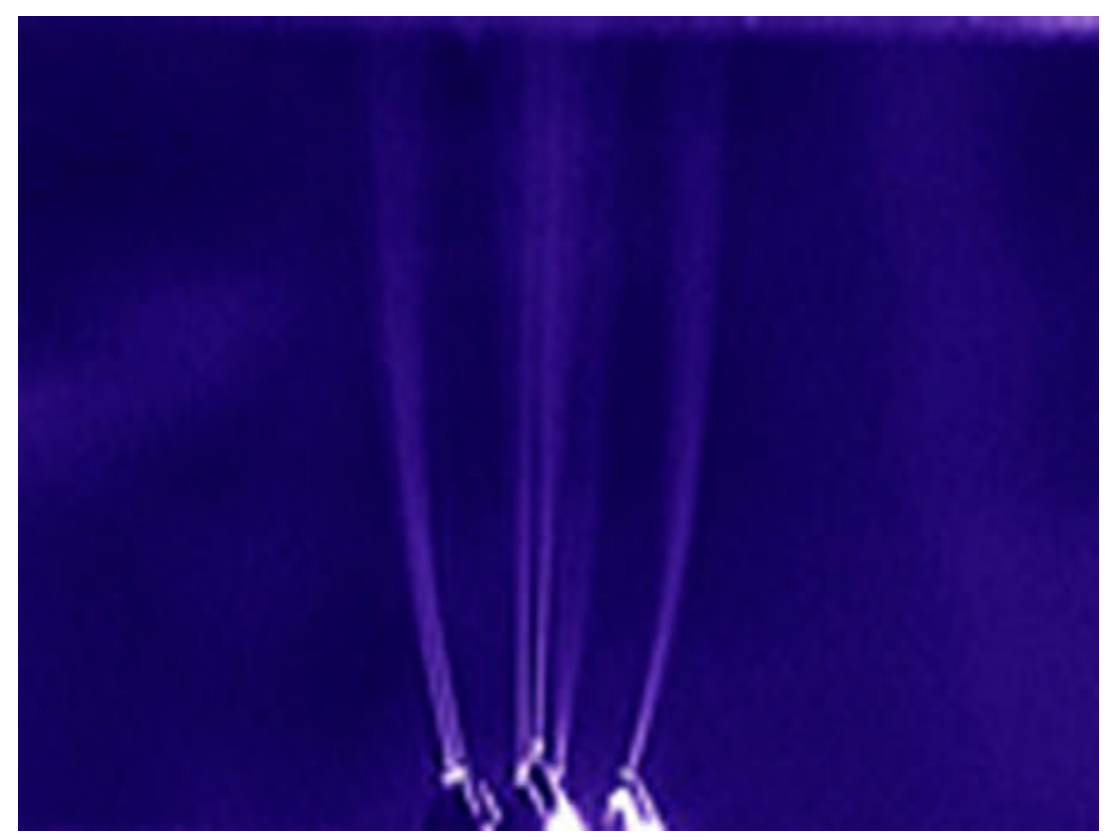

Fig.2. Kyritsis et al. 


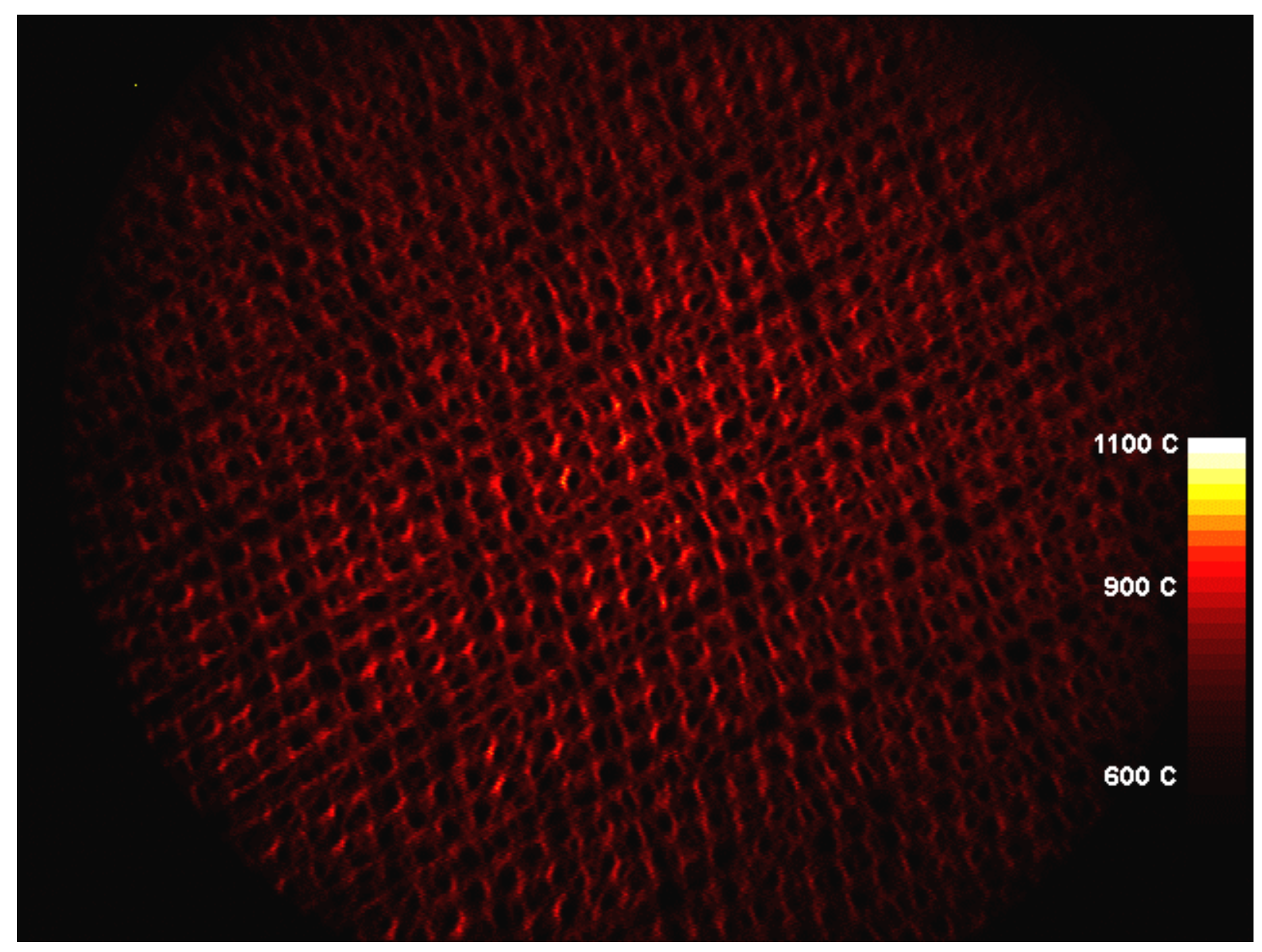

Fig.3 Kyritsis et al. 

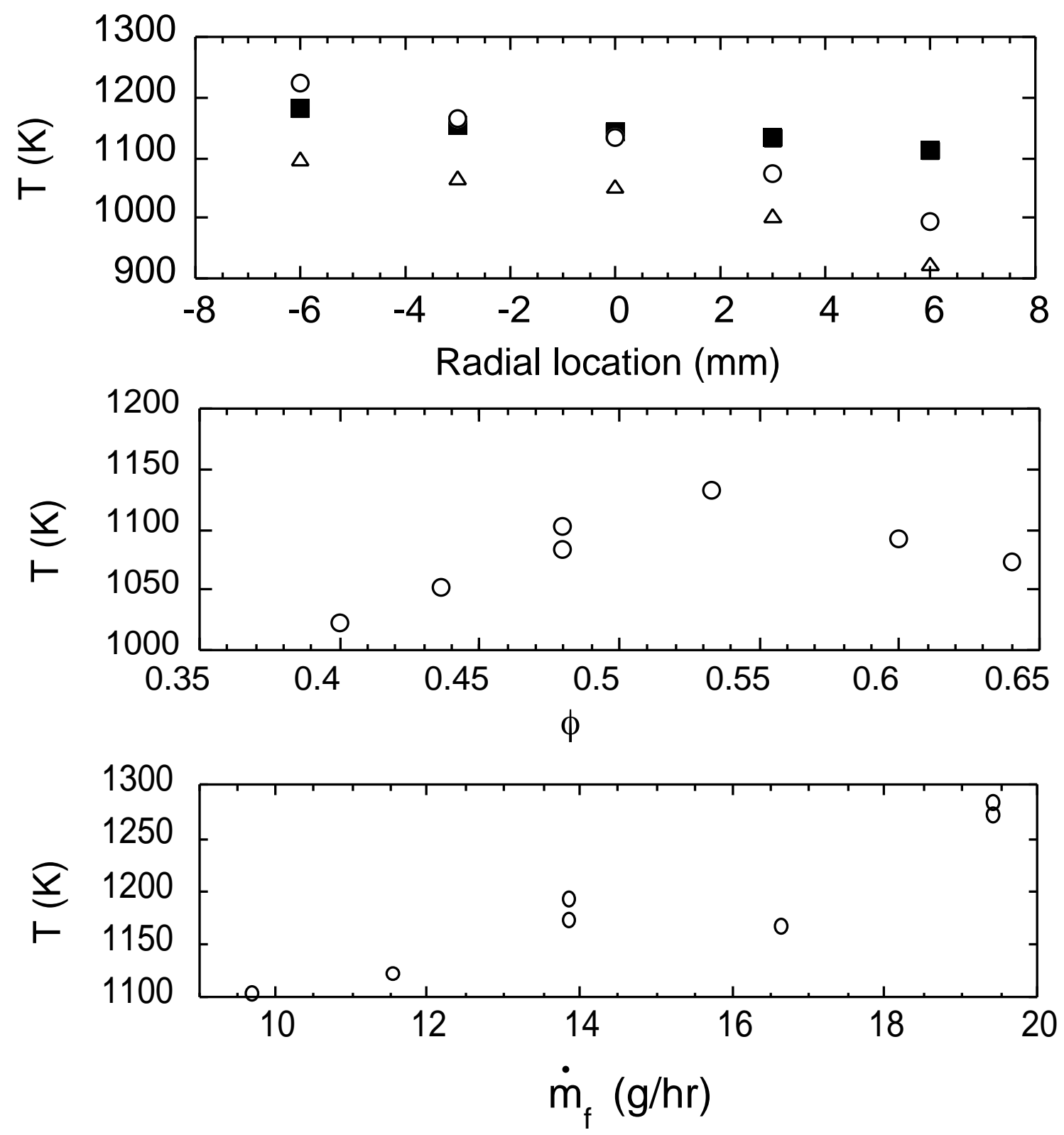

Fig.4a,b and c: Kyritsis et al. 


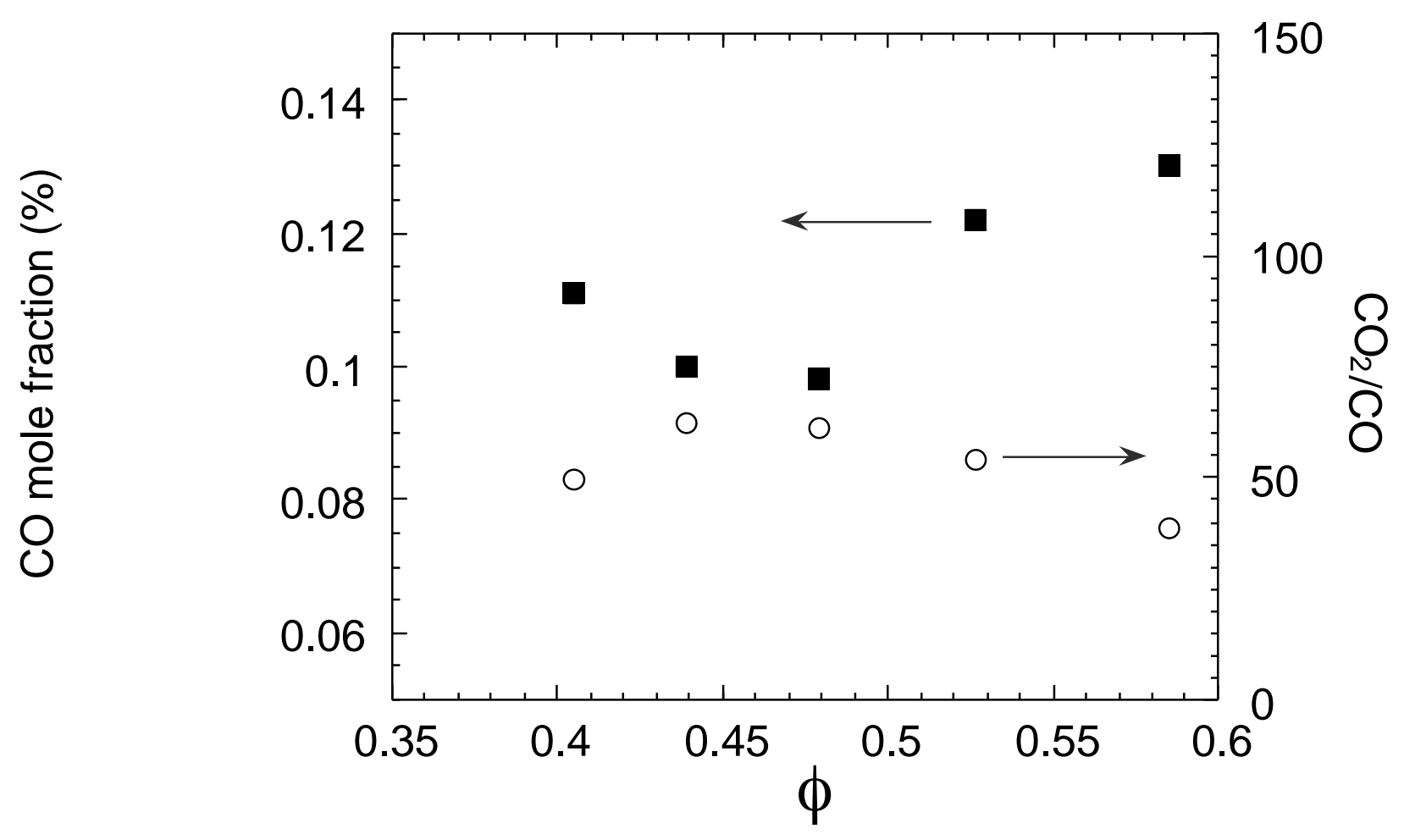

Fig.5 Kyritsis et al. 


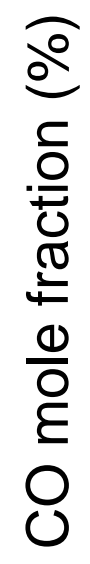

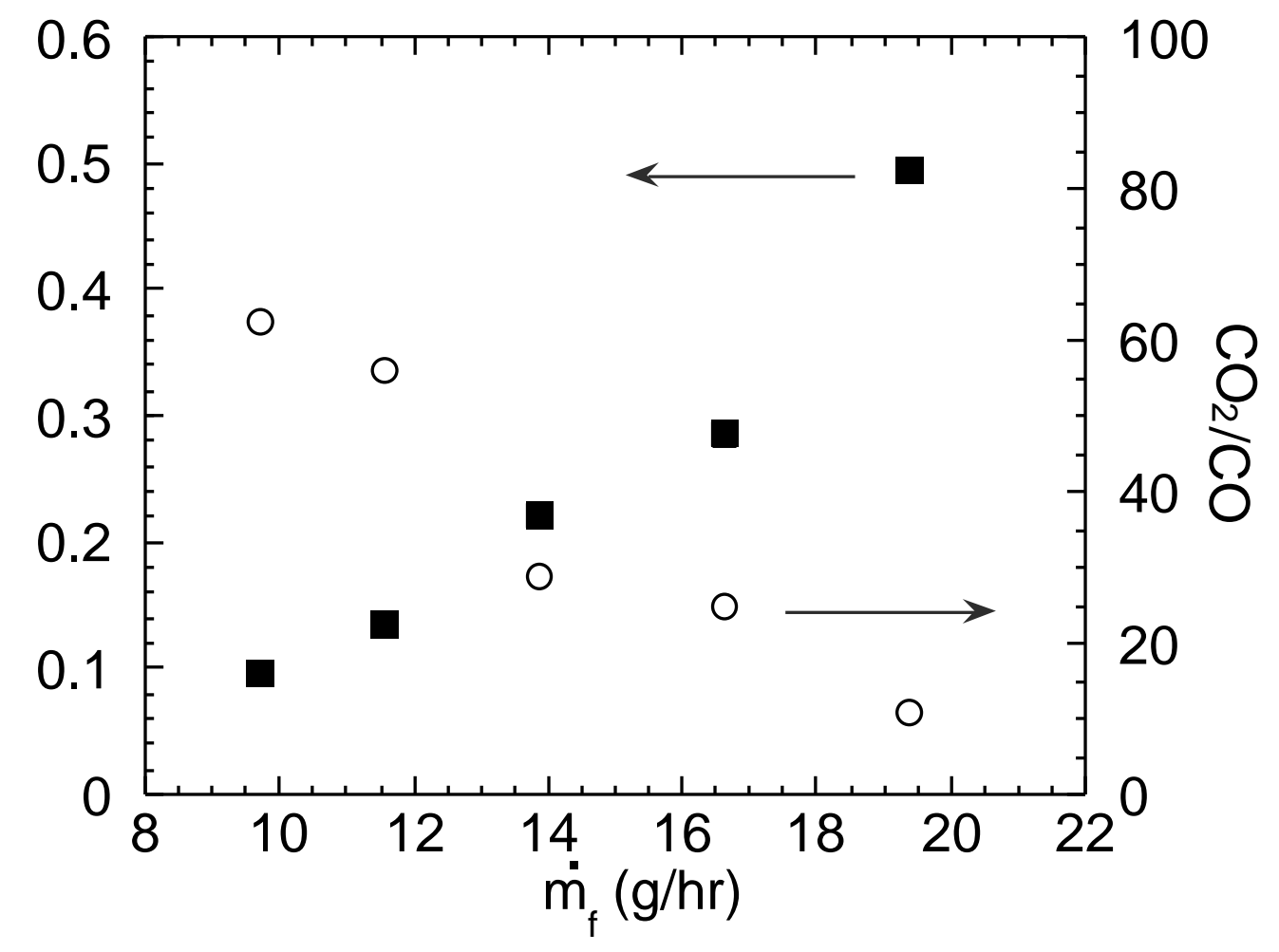

Fig.6 Kyritsis et al. 